\title{
Recovery from a hot water leakage at the Tokamak ASDEX Upgrade
}

Volker Rohde, Albrecht Herrmann, Martin Balden, Detlef Bösser,

\author{
Katja Hunger, Gerd Schall, Michaela Uhlmann, Thomas Vierle and ASDEX Upgrade Team
}

Max Planck Institut für Plasmaphysik, Boltzmannstrasse 2, 85478 Garching, Germany

\begin{abstract}
During a regular vessel baking after a manned access a leakage of a heating/cooling pipe released about 1001 of hot water into the vacuum vessel of ASDEX Upgrade (AUG). Erosion of a ten years old Cu gasket by water during baking causes the leak. At plasma facing components the water steam forms white remnants as it reacted with the boron-hydride layers used for wall conditioning and cause locally oxidation of stainless steel. After cleaning no significant damages remained. As some remote parts of AUG are not heated water condensates at these locations and stays there for weeks. At these ports serious damages was found at certain kinds of electrical feed through and $\mathrm{Al}$ gaskets. Completely removal of water within 4 weeks is needed to avoid this kind of problems. To identify and fix the most dominate leak a step-by-step approach was used. After repair AUG was successful operated for 9 months till the next regular maintenance.
\end{abstract}

Keywords: Tokamak, vacuum, conditioning, water ingress

\section{Introduction}

In most fusion devices water is used to cool down the plasma facing components (PFCs) after plasma discharges, which requires operation of high pressured water infrastructure inside a vacuum vessel. The same technique will be used in future fusion devices, but causes an issue in case of water coolant loss during operation. Safety studies identified this as critical scenario and the behavior has to be study for licensing. Extensive investigations and simulations on water ingress in a hot activated tokamak had been published [1]. At the medium-sized tokamak ASDEX Upgrade (AUG) [2], which is in operation since 1991, the same system is also used for vessel baking at $150{ }^{\circ} \mathrm{C}$ after a vent. In November 2017, during a regular vessel baking, a gasket of a water pipe failed, which led to the ingress of hot water steam into the vacuum vessel. In this contribution, this event, instant damages caused by the hot water, slow degradation of components due to long exposure to hard-to-remove water in remote areas, the recovery phase, and the wall condition for the next experimental campaign are reported.

\section{Water ingress event}

Typically, baking is planned only once a year after the maintenance period, however failures during plasma operation may require additional manned entries and subsequent baking. In
October 2017 damage to a component during a plasma discharge caused the inlet of about 101 of cooling water at room temperature into the vacuum vessel. This required an opening of the device to remove the main part of the water using a vacuum cleaner. No other damage occurred in the course of this event. After the vessel had been opened for one week to allow for the repair work, the normal condition procedure, which requires a baking of the vessel at $150{ }^{\circ} \mathrm{C}$ to remove the ad- and absorbed water from the graphite, was started. Graphite is used as a substrate for the W coated PFCs [3] in AUG because of its smaller weight and reduced costs compared to bulk W. As the maximum baking temperature is limited to 150 ${ }^{\circ} \mathrm{C}$ due to the materials used for plasma diagnostics, typically $100 \mathrm{~h}$ are needed to reduce the water vapor partial pressure to $1.0 \times 10^{-7} \mathrm{mbar}$, the required level for plasma operation.

On November 19, 2017, after $83 \mathrm{~h}$ of baking at flat top temperature the base pressure started to rise continuously. Residual gas analysis and pressure behavior indicated a water leakage. An attempt was made to identify and isolate the responsible water channel. During these tests the pressure increased further and reached the maximal operating value for the turbo pumps, and the pumping system was switched off by a safety interlock. The cooling down sequence was started, lasting about $24 \mathrm{~h}$ to reach the room temperature to avoid thermal stress at the 
vessel and flanges. A restart of the pumping system, using only the roughing pumps yielded a pressure of about 20 mbar at the pumping system. Gauges at the vessel were affected by high temperature and water vapor, but as vacuum could be kept, it is assumed that at only water steam was present at this time. The restart using the roughing pumps could reduce the base pressure, but the pumps were switched off as it was not possible to isolate the water leakage. Finally, about $8 \mathrm{~h}$ after the first pressure rise the in-vessel pressure reached 1000 mbar at a vessel temperature of about 110 ${ }^{\circ} \mathrm{C}$. AUG is protected by a bursting disc (400 mbar overpressure) which was not activated.

The base pressure of 20 mbar for active pumps indicated that a significant amount of water was already in the vessel at flat top temperature of $150{ }^{\circ} \mathrm{C}$, but at a water temperature of $90{ }^{\circ} \mathrm{C}$, the water loss in the cooling channels reached about $30 \mathrm{l} / \mathrm{h}$. In total about $100 \mathrm{l}$ of water entered the vacuum vessel. Some in-vessel components are not water cooled/heated, which allow personnel access to the torus hall for visual inspection, the vessel was at atmospheric pressure and water drops were observed on the inside of view ports.

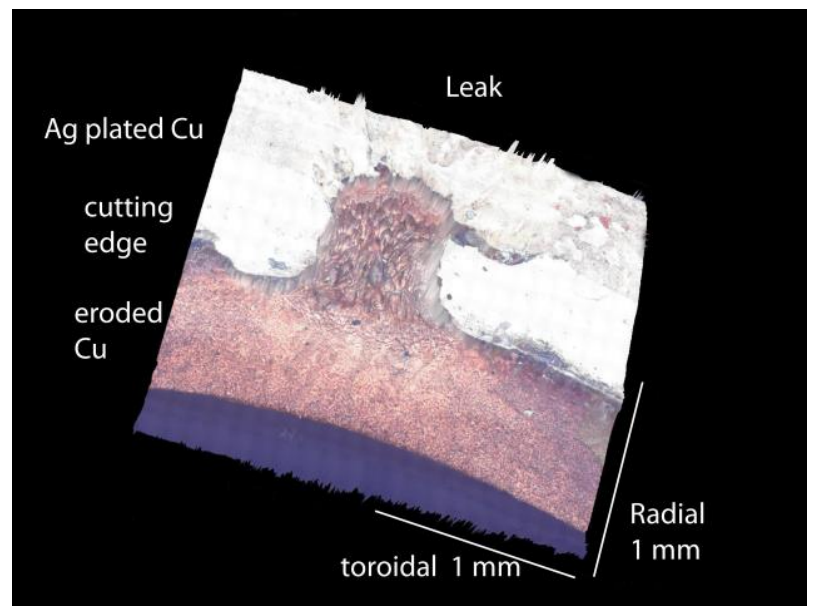

Fig. 1 Microscopic 3D-view of the gasket under an angle of $45^{\circ}$ from top. The position of the cutting edge is at the transition from the $\mathrm{Cu}$ (brown) to the $\mathrm{Ag}$ (white). In the middle strong erosion of the gasket indicates the leak.

After accessing the vacuum vessel the leak could be identified at a $\mathrm{Cu}$ gasket in the cooling circuit of an NBI port protection. Most gaskets in water channels at AUG use a special $\mathrm{Cu}$ coaxial double seal design. The double seal, with the intermediate volume connected to an auxiliary vacuum system, allows for testing of the installed components and avoids water ingress to the main vacuum in case of a failure of a seal. Unfortunately, space restrictions did not allow the usage of this technique at this location.

Here a $\mathrm{Cu}$ gasket of $20 \mathrm{~mm}$ diameter with $\mathrm{Ag}$ coating in a CF like flange was used. The failed gasket was strongly eroded: only $0.1 \mathrm{~mm}$ of originally $2 \mathrm{~mm}$ thick $\mathrm{Cu}$ were left. Figure 1 shows a microscopic 3D view of the eroded $\mathrm{Cu}$ gasket at the position leading to the leak. It turned out that the erosion was due to the use of deionized water, which was required during plasma operation and was also used during baking. By uptake of $\mathrm{CO}_{2}$ from the air the water got a $\mathrm{pH}$-value of about 5 , which caused erosion during the high temperature phase of the baking procedure. The Ag coating, which should prevent erosion, did not really help. As the last replacement of the sealing was not documented, the total lifetime of this sealing is not exactly known, but it was operated for at least 10 years and about $2500 \mathrm{~h}$ at baking temperature.

To prevent erosion of $\mathrm{Cu}$ gaskets in the future, the cooling system was extended so that the invessel water channels can be emptied during baking. Moreover, $\mathrm{NaOH}$ is now added during baking to adjust the water to $\mathrm{pH} \sim 9$.

\section{In-Vessel cleaning}

After the incident an in-vessel inspection revealed about 1001 of water found mostly below the lower divertor structure. Condensed clear water was also found at remote areas that were connected to the vacuum vessel during the event. At the PFCs, which were coated by a borohydride layer for wall conditioning [4], white crystals were found. Obviously, the layers were dissolved by the hot water steam, producing boric acid. A fraction of this acid was dried during a $48 \mathrm{~h}$ venting in preparation of a personnel access to the vessel. Figure 2 shows a stainless steel protection plate at the low field side midplane. White crystals are borate, the brownish layers turned out to be rust produced from stainless steel by the hot boric acid. 
In a first step most of the water was removed using a vacuum cleaner. The layers could be removed by a commercial water steam cleaner in combination with a vacuum cleaner. During this time the staff working inside the vessel used breathing masks and personal protection gloves.

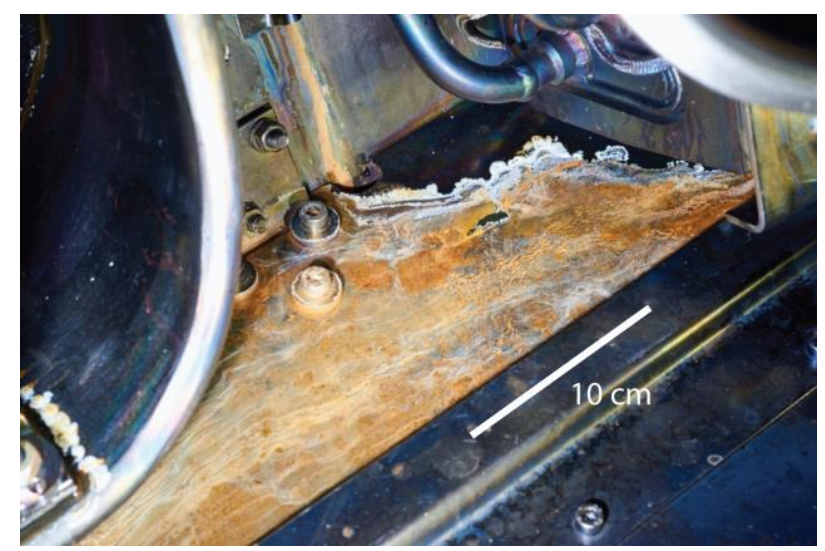

Fig. 2 The Status of the vessel after the opening. A stainless steel protection at the low field side midplane is shown. The white crystals are borate, brownish layers are rust.

\section{Damages}

After the vessel cleaning the tightness of the water cooling system inside AUG was checked. It turned out that the second seal of the coaxial flanges of 12 out of 18 channels was not tight, presumably due to temperature gradients during the water inlet event. All 256 coaxial gaskets were replaced for this reason.

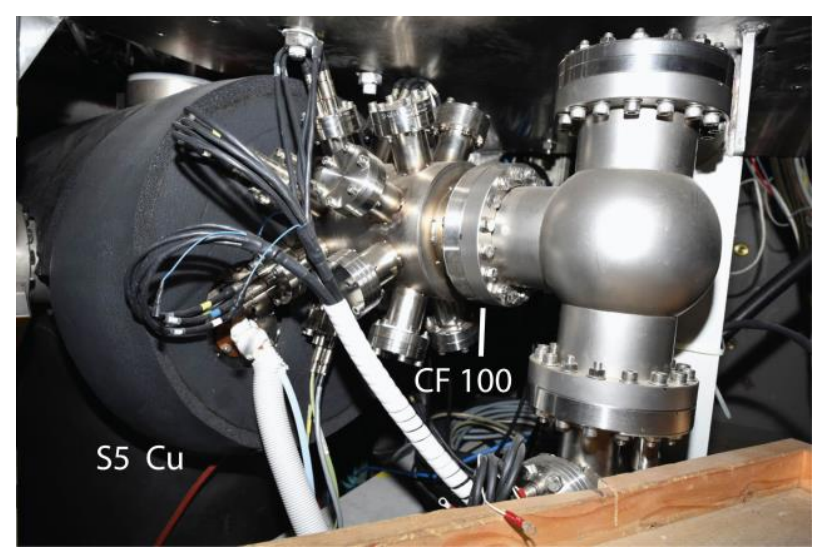

Fig. 3 One of the flanges used for the connection of the SXR cameras.

During our baking procedure, the vacuum vessel and the in-vessel components are heated by hot water. All flanges and most of the adaptors, gate valves and feed throughs are heated electrically. Not all locations are heated to the same temperature: Some parts are not heated to avoid damages to the diagnostics installed, in other places the electrical heating turned out to be not sufficient or damaged or even missing. For normal operation of AUG this is a minor problem. Most of these locations are far away from the plasma and are not warmed up during plasma operation, i.e. almost no water is desorbed which might hinder operation. After the incident, however, condensed water was found at gate valves, windows and other locations. The water was removed, the gate valves were opened and the seals were replaced or cleaned and finally tested.

Rust is known as potential starting point for oxidation of stainless steel. Especially at bellows, which are made from a thin steel sheet, care was taken to remove the rust mechanically after drying of the bellows.

To remove the residual water dry air was purged into the vessel, so after several days no water was visible in the vessel anymore.

AUG is equipped with many diagnostics, which had been upgraded and enhanced over the years. For example the soft x-ray cameras now cover 210 lines of sight. As each channel requires two electrical feed through pins more and more flanges had been installed. To simplify the system standard flanges had been used for this purpose. An electrical feed through isolated with ceramics was selected, allowing a compact design. As all flanges use $\mathrm{CF}$ gaskets and the individual components had been tested before installation, safe vacuum operation was possible, even with a large number of flanges. Figure 3 shows the hedgehog design used at AUG to accommodate the large number of feed through which are required by advanced diagnostics. Whereas most flanges of AUG are electrically heated during baking, these components were not, because during normal plasma operation the effect on the main chamber vacuum is tolerable due to the bad gas conductance to the feed through volume. 


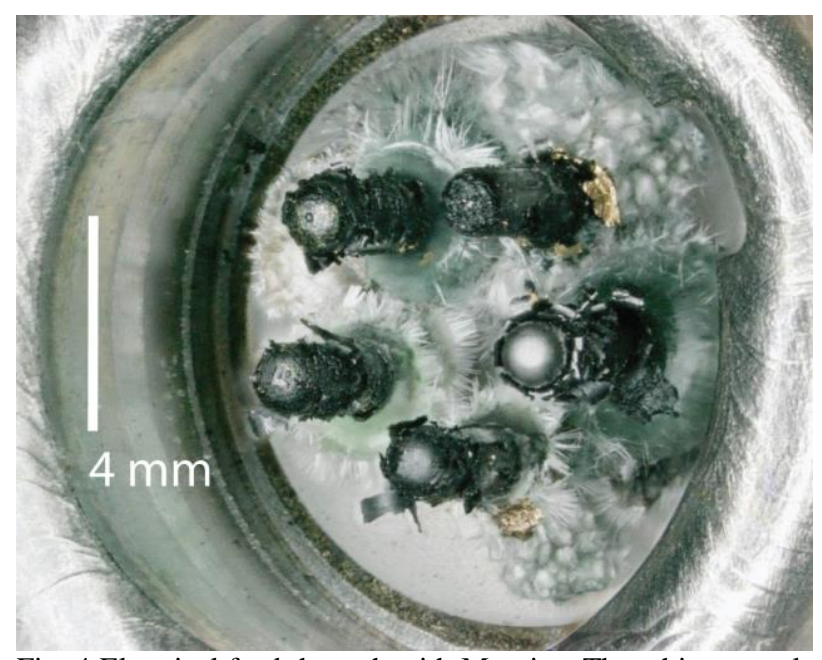

Fig. 4 Electrical feed through with Mo pins. The white crystals are Molybdenum Oxides, remnants of the Au plating are also found.

Inspection of the remote flanges showed that some of these positions were almost completely flooded by the water even after 20 weeks of the main chamber venting with dry air. The transport of the water to these locations during the incident can be explained by the heat pipe effect: when the incident happened, the wall was hot, water turned into steam, and steam reached all locations inside the vacuum vessel. At remote locations the wall was cool, so that steam condensed and water accumulated in these areas. A method to dry these locations effectively will be discussed below.

It turned out that the consequences for the feed through depended on the materials used for the pins. Brazing of pins into an $\mathrm{Al}_{2} \mathrm{O}_{3}$ ceramic requires a match of the thermal expansion, so only some materials are suitable. Whereas for pins produced out of $\mathrm{BeCu}$ or Kovar almost no oxidation is observed, Mo pins were strongly affected. Even Au plating did not help to protect the material from oxidation. An example is shown in Figure 4. The white crystals are molybdenum oxides which strongly influence the resistance of the contacts. After cleaning and sand blasting of the insulation and the pins the electrical properties could be restored, but vacuum tests showed that the brazing may leak due to strong erosion of the Mo close to the brazing location. So all flanges with this kind of feed through, in total 92 flanges with typically 6 connectors and up to 10 pins per connector, were disassembled and tested. Whereas only $3 \%$ of flanges removed and dried within 4 weeks after the event showed a leakage, about $51 \%$ of flanges removed after 20 weeks were damaged. Clearly the vessel has to be dried within 4 weeks to avoid oxidation of feed through containing Mo. All the affected feed thoughts were replaced.

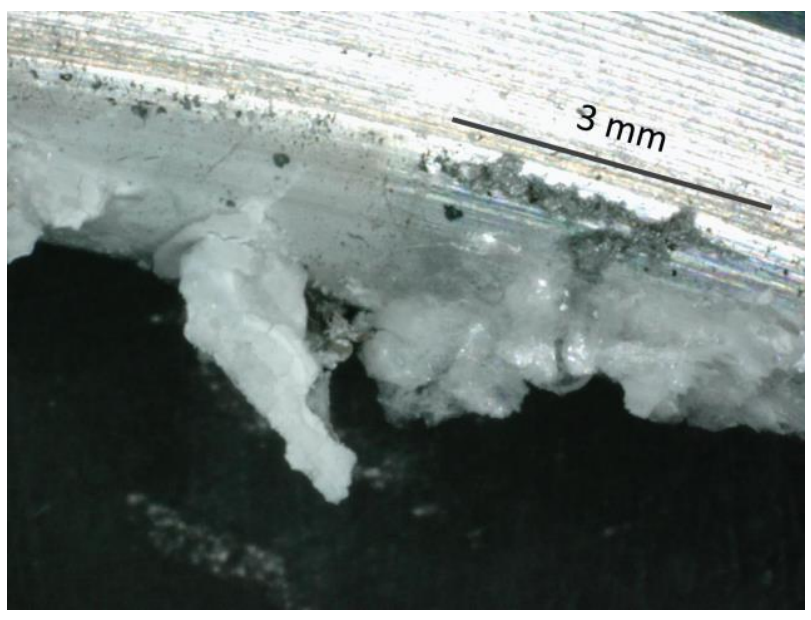

Fig. 5 Damaged Helicoflex gasket. Erosion and $\mathrm{Al}(\mathrm{OH})_{3}$ were found

\section{Recovery}

The shutdown was extended to execute the scheduled maintenances and upgrades. Pumping was started on June 8, 2018. A vacuum pressure of only $3.8 \times 10^{-3}$ mbar was reached after $24 \mathrm{~h}$, and the routine leak search procedure was started. As usually a commercial leak detector was attached to the pumping system and $\mathrm{He}$ was released to identify the position of the leak. Three flanges in the upper part of the vessel were identified as main leaks.

The vacuum vessel of AUG consists of 16 segments [2], each has 3 vertical ports on the top and bottom, respectively, and up to 4 horizontal ports at the low field side. Figure 7 shows a poloidal cross section of AUG with the ports. The vacuum vessel of AUG is fixed inside the toroidal field coil system, which is supported by a cast-iron shell. Outside of this shell, the poloidal control coils are installed, supported by a steel structure. The ports are welded onto the vessel and the first flange is located inside the poloidal field coil system. The ports are extended to allow access from outside the poloidal field support structure, where more space is available for the 
installation of components. The first flange of the vertical ports is sealed with Helicoflex gaskets [5]. This kind of gasket, consisting of an $\mathrm{Al}$ tube which is strengthened by an internal spring, is known for its long term reliability. This construction was operated without problems for almost 30 years. The port extensions of the vertical ports were mounted during the assembly phase before the installation of the poloidal field coils. They were never touched since the installation because of the very limited accessibility

To remove these gaskets special equipment was developed to open the flanges and remount them with new gaskets. Unfortunately, all electrical and optical connections, which are using these ports, had to be disassembled.

Gaskets, which showed a leakage, were covered by white foam which turned out to be $\mathrm{Al}(\mathrm{OH})_{3}$. Figure 5 shows a picture of the damaged helicoflex gasket. Due to this oxidation, Al showed erosion traces, which finally caused a failure of the gaskets. Water plays a major role for the oxidation. Helicoflex gaskets, mounted at the main ports in the midplane, where the water was removed within some days, were not damaged. Tests with unused Al gaskets showed that they were not eroded within 3 months with clean water only. If some acid, as produced by the boron, was added or the Al was in contact with stainless steel, oxide production was found after some weeks. Even though the mechanism is not fully understood, it is clear that $\mathrm{Al}$ gaskets have to be dried within one week to avoid damages.

Most of the ports using Helicoflex gaskets are used to supply diagnostics with cabling or optical fibers. As at AUG in total 72 Helicoflex flanges are used, it was not possible to replace all within the time allocated for maintenance and repair.

At this state it was not clear, where leaks were located. Leak detection by $\mathrm{He}$ only works reliably if no bigger leak is close by. As the access to the damaged flanges was strongly restricted, shielding of the identified leaks from He was not possible. For this reason a step by step leak removal was carried out. AUG was pumped down and leaks were identified. Residual gas analysis was used to classify the importance of the leakage by the fraction of $\mathrm{N}_{2}$ replaced by He. After a clear identification of leaks, the vessel was vented and the leaking gaskets were replaced. Then the next cycle was started. In total 3 cycles were needed to fix the main leaks.

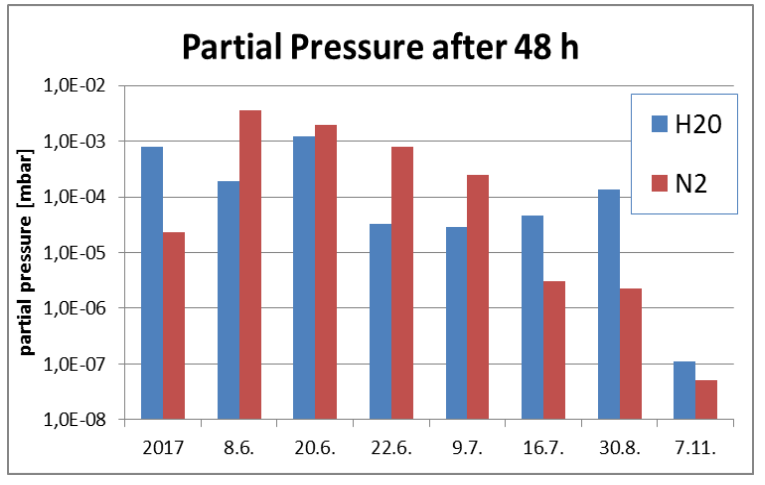

Fig. 6 Development of the water and nitrogen partial pressures for the different pump down cycles. For reference data for 2017 before the final leak fixing and for plasma operation (7.11.) are shown.

The sensitivity of the He leak tests is limited by the amount of $\mathrm{D}_{2}$ remaining in the PFCs from previous plasma operation. To increase the sensitivity the in vessel Liquid He cryopump was used, enhancing the sensitivity by a factor 10 , as $\mathrm{D}_{2}$ is removed with a high pumping speed, but He is not affected.

During these pump - leak test - repair - pump cycles the pressure decreased continuously, as shown in figure 6 , and the sensitivity for leak detection rose. Finally, leaks were found in another type of electrical feed through, which are used for in-vessel magnetic pick-up coils. At AUG 17 flanges of this type, with up to 27 bipolar feed through are installed. Analysis showed that the pins themselves were not affected but a brazing, which is needed to interface the stainless steel to the Mo, was eroded. As the magnetic pick-up coils are needed for plasma control the flanges had to be replaced before plasma operation.

\section{Restart}

As the production and testing of new flanges needed some time, blank flanges were used to replace the leaky flanges temporarily and a test baking was started to be sure that the remaining damaged parts are stable and no leakages are opened. 
After installation of the new feed through the pump down started on August 30, 2018, followed by an electrical test of the pick-up coils and a 9 day baking at $150{ }^{\circ} \mathrm{C}$. A final leak search found a damaged re-entry port, which could be differentially pumped and an electrical feed through, which could be stabilized using epoxy.

On September 25, 2018, a Boronization [4], including an $8 \mathrm{~h}$ He glow discharge [6], was applied to optimize the wall conditions. Operation was started the next day. On September 27, 2018, plasma operation was started. After the break tests of safety systems and an adjustment of the control system was needed. About $0.4 \mathrm{~s}$ of plasma with up to 400 kA was reached that day. Another technical issue hindered operation for 7 weeks. On November 20 plasma operation was resumed. To reactivate the boronization $30 \mathrm{~min}$ of $\mathrm{He}$ glow discharge (He GD) was used and an ohmic $800 \mathrm{kA}$ discharge which ended after $3 \mathrm{~s}$ in a density limit was achieved. For the next experimental day again 30 min of He GD was applied and a first plasma discharge using 2.5 MW of NBI and additional ICRH heating was stable. On that day in total 14 discharges with heating power up to $16 \mathrm{MW}$ were done for commissioning. During this day only $20 \mathrm{~s}$ of He GD was needed to optimize plasma ramp up. After a second boronization on November 26 normal plasma operation was started following the physics program.

Finally on November 30, 2018, AUG was vented by $\mathrm{N}_{2}$ to replace the tentatively fixed leakages. In the following a successful operational campaign lasting 8 months was performed and concluded as planned.

\section{Summary and conclusions}

ASDEX Upgrade was designed to be in operation for about 15 years. As many systems had been continuously upgraded and enhanced successful operation is still possible after about 30 years. However, to prolong the lifetime of some components they need special attention. Erosion of thin $\mathrm{Cu}$ gaskets was observed earlier at VCR flanges. The $\mathrm{Cu}$ gaskets were replaced by steel ones. The lifetime of CF type seals was not discussed. After this event all $\mathrm{Cu}$ gaskets, which were in contact with water, were replaced. In addition, erosion will be reduced by adding $\mathrm{NaOH}$ to water during the baking to increase the $\mathrm{pH}$ value to $\mathrm{pH} \sim 9$.

A hot water leakage is a kind of worst case scenario as the hot steam in combination with boron is very aggressive and boron salts are deposited on in-vessel surfaces. Removing these deposits was very effectively done with a commercial steam cleaner in combination with a vacuum cleaner. Serious damages were found at certain kinds of electrical feed throughs and $\mathrm{Al}$ gaskets. The positions of the damaged parts are indicated in the poloidal cross section of AUG depicted in figure 7. All these damages are located in remote areas and developed on a time scale of serveral weeks. Feed through removed and dried within 4 weeks showed no damage. For this reason fast drying of not only the main vessel walls but also the remote areas is needed to stop oxidation.

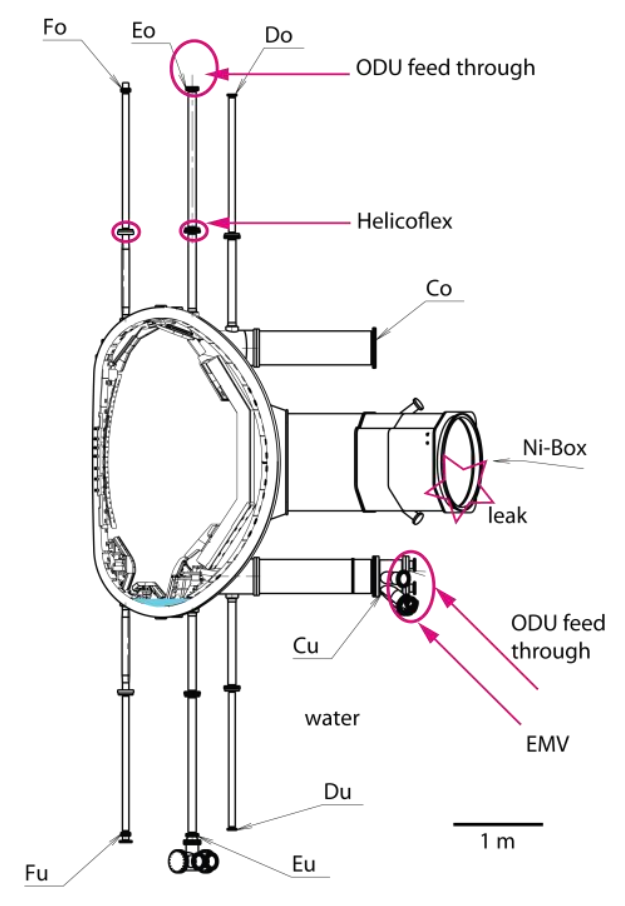

Fig. 7 cross section of AUG showing the position of the damages

It turned out that for a complicated vacuum vessel with gaps and badly pumped vessel extensions water removal by dry air did not work. Baking to remove the water will produce more damages due to chemical reactions and will again transport water to cold locations. The most effective way seems to be pumping 
down to remove the water. Large amounts of water will be frozen by this procedure; frozen water may cause damage and prevent evaporation of water. To avoid freezing of water we recommend a 'pump and purge' procedure as the best way to remove the water. In the pumping phases the vessel should be pumped down to pressures even below the water vapour pressure of about $20 \mathrm{mbar}$, as

\section{Acknowledgments}

The authors like to thank the technical staff, especially W.Zeidner, M.Ebner, V.Brack, and T.Hohmann, J.Henning and F.Springer who developed solutions for all the problems rising during this time.

This work has been carried out within the framework of the EUROfusion Consortium and has received funding from the Euratom research and training programme 2014-2018 and 2019-2020 under grant agreement No 633053. The views and opinions expressed herein do not necessarily reflect those of the European Commission.

\section{References}

[1] P.Humrickhouse, B.Merrill, Initial Development of MELCOR 2.2. for fusion, this proceedings

[2] A.Herrmann et al. special issue on ASDEX Upgrade, FUSTE8 3 (2003) 569-748

[3] R.Neu et al., Plasma wall interaction and its implication in an all tungsten divertor tokamak,PPCF 49 (2007), B59-B70

[4] V.Rohde et al., Wall conditioning in ASDEX Upgrade, J.Nucl.Mat., 363-365 (2007) 1369-1374

[5] https://technetics.com/produkte/dichtungslosungen/metall dichtungen/helicoflex/

[6] T.Härtl et al.,Optimization of the ASDEX Upgrade glow discharge, Fus .Eng. Des. 124 (2017) 283-286 this pressure will not be reached in the remote areas due to the bad conductance. Afterwards the vessel should be purged by clean $\mathrm{N}_{2}$, to melt frozen water by increased heat conduction. Then start the next cycle and repeat until the water partial pressure is below a critical value. A differentially pumped RGA system is needed to monitor the water removal. 